\title{
Numerical Simulation and Analysis of Hot Cracking in the Casting of Fork
}

\author{
Wang Mingguang, Pu Yong
}

Chongqing Key Laboratory of Micro/Nano Materials Engineering and Technology, Chongqing University of Arts and Science, Chongqing 402160, China

\begin{abstract}
In the investment casting of shifting fork, hot cracking is a common defect. In order to analyze the hot cracking in the investment casting, the ProCAST software was adopted, and the investment casting process was simulated, The filling field, temperature field and stress field were analyzed, and the cause of crack was predicted. Results show that as the local area receives larger tensile stress from around, the shrinkage cavity appears; as a result, hot cracking occurs. By decreasing the pouring temperature, increasing preheating temperature of the shell, or chamfer angle of the fork, the casting stress can be reduced, and thus the crack will be avoided.
\end{abstract}

Key words: hot cracking; fork; numerical simulation.

Hot cracking is a common defect in the process of investment casting, which affects the quality of casting products seriously, and shortens the service life of products $^{[1,2]}$. With the development of computer technology and computational method, numerical simulation technology is improved constantly; it can predict stress and strain, provide an effective method for the prediction of hot cracking, and improve casting quality.

The Pro-CAST software is used for numerical simulation commonly, which can simulate the casting process. It can predict defects effectively and provide reference to improve the casting quality. In the present paper, the Pro-CAST software was applied to simulate and analyze hot cracking, which can enhance the production rate and has a great significance.

\section{Model and Boundary Condition}

\subsection{Mathematical model for fluid}

In the molding filling, the mathematical model is the basis and premise of the finite element for fluid, which is regarded as the incompressible fluid. The coupled equations of temperature field and flow field are shown as below.

The continuity equation is a mathematical expression of the law of mass conservation, and used for fluid generally. The motion equation can be used for the ideal fluid and viscous fluid. The mathematical expression can be seen as below ${ }^{[3]}$ :

$$
D=\frac{\partial u}{\partial x}+\frac{\partial v}{\partial y}+\frac{\partial w}{\partial z}=0
$$

wherein: $D$ is a divergence; $u, v, w$ is the velocity vector in $x$, $y, z$ direction component in the coordinate system.

Energy equation ${ }^{[4]}$ is as follows:

$$
\frac{\mathrm{d} e}{\mathrm{~d} t}+\rho \frac{\mathrm{d}}{\mathrm{d} t}\left(\frac{1}{\rho}\right)=\frac{1}{\rho} \operatorname{div}(\lambda \operatorname{grad} T)+\frac{\varphi}{\rho}
$$

wherein: $e$ is the internal energy of the fluid; $\rho$ is density; $\varphi$ is dissipation function.

\subsection{Hydrodynamics model}

The thermo-elastic model is used in thermal stress simulation commonly. In the model, the relationship between stress and strain complies with the following equation ${ }^{[5]}$ :

$$
\mathrm{d} \sigma_{\mathrm{e}}=D_{\mathrm{e}} \mathrm{d} \varepsilon_{\mathrm{e}}
$$

Received date: April 25, 2016

Foundation item: Science and Technology Projects of Chongqing Education Commission (KJ1401123); Foundation and Frontier Research Program Projects of Chongqing (cstc2014jcyjA50033)

Corresponding author: Wang Mingguang, Master, Chongqing Key Laboratory of Micro/Nano Materials Engineering and Technology, Chongqing University of Arts and Science, Chongqing 402160, P. R. China, E-mail: wmg166@163.com 
where $\mathrm{d} \sigma_{\mathrm{e}}, D_{\mathrm{e}}$ and $\mathrm{d} \varepsilon_{\mathrm{e}}$ are elastic stress incremental, elastic modulus matrix and elastic strain increment, respectively. The following subscripts e, $\mathrm{p}$ and $t$ denote elastic, plastic and heat, respectively.

In the thermal elastic-plastic model, the strain increment can be expressed as follows ${ }^{[6]}$ :

$$
\mathrm{d} \varepsilon=\mathrm{d} \varepsilon_{\mathrm{e}}+\mathrm{d} \varepsilon_{\mathrm{p}}+\mathrm{d} \varepsilon_{\mathrm{t}}
$$

Stress and strain conform to the following relationship ${ }^{[7]}$ :

$$
\mathrm{d} \sigma=D_{\text {ep }}\left(\mathrm{d} \varepsilon_{\mathrm{e}}+\mathrm{d} \varepsilon_{\mathrm{p}}\right)=D_{\mathrm{ep}}\left(\mathrm{d} \varepsilon-\mathrm{d} \varepsilon_{\mathrm{t}}\right)
$$

wherein, $D_{\text {ep }}$ is the matrix of elasto-plastic modulus.

Thermal contraction and strain increment including incremental elastic modulus and linear expansion coefficient vary with temperature, which can be expressed as:

$$
\left\{\mathrm{d} \varepsilon_{\mathrm{t}}\right\}=\{\alpha\} \mathrm{d} T+\left(T-T_{0}\right) \partial\{\alpha\} / \partial T+\partial[D]_{\mathrm{e}}^{-1} / \partial T\{\sigma\}
$$

wherein: $T_{0}$ is the initial temperature; $T$ is instantaneous temperature; $\alpha$ is linear expansion coefficient. Plastic strain increment is determined by the size and direction of fluid criteria:

$$
\left\{\mathrm{d} \varepsilon_{\mathrm{p}}\right\}=\mathrm{d} \bar{\varepsilon}_{\mathrm{p}} \frac{\partial \bar{\sigma}}{\partial\{\sigma\}}=\frac{1}{H^{\prime}}\left[\frac{\partial \bar{\sigma}}{\partial\{\sigma\}}\right]^{T}\{\mathrm{~d} \sigma\} \frac{\partial \bar{\sigma}}{\partial\{\sigma\}}
$$

wherein: $H^{\prime}$ is the plastic hardening modulus of the material, which can be obtained by a simple tensile curve.

\subsection{Thermal boundary conditions}

The heat $(\Delta Q)$ transfers between the casting and shell, which can be expressed as follows ${ }^{[6]}$ :

$$
\Delta Q=h\left(T_{1}-T_{2}\right)
$$

wherein: $h$ is heat transfer coefficient of the interface; $T_{1}$ and $T_{2}$ are temperatures of the two interfaces, respectively ${ }^{[7]}$.

Meanwhile, there is also a radiant and convective heat transfer process between the casting and the environment.

$$
\Delta Q=h_{1}\left(T-T_{\mathrm{a}}\right)+\sigma \varepsilon\left(T^{4}-T_{\mathrm{a}}^{4}\right)
$$

wherein: $h_{1}$ is convective heat transfer coefficient of shell mold or sand box between other surface with the environment; $T$ is the temperature of the shell mold or sand box; $T_{\mathrm{a}}$ is the ambient temperature; $\varepsilon$ is radiation heat transfer coefficient.

\section{Fork Structure and Casting Technology}

\subsection{Fork structure and hot cracking}

The fork structure is shown in Fig.1a, Fig.1b is a selected area of Fig.1a, and the cracked area can be seen in Fig.1b. The qualified rate is low; therefore, it is necessary to analyze the cause of crack defects, and provide theoretical basis to improve the technology.

The fork for casting is the thin-walled structure, ZG310-570 is used for investment casting, and the casting part is shown in Fig.1. 24 pieces are a group for casting, as shown in Fig.2.

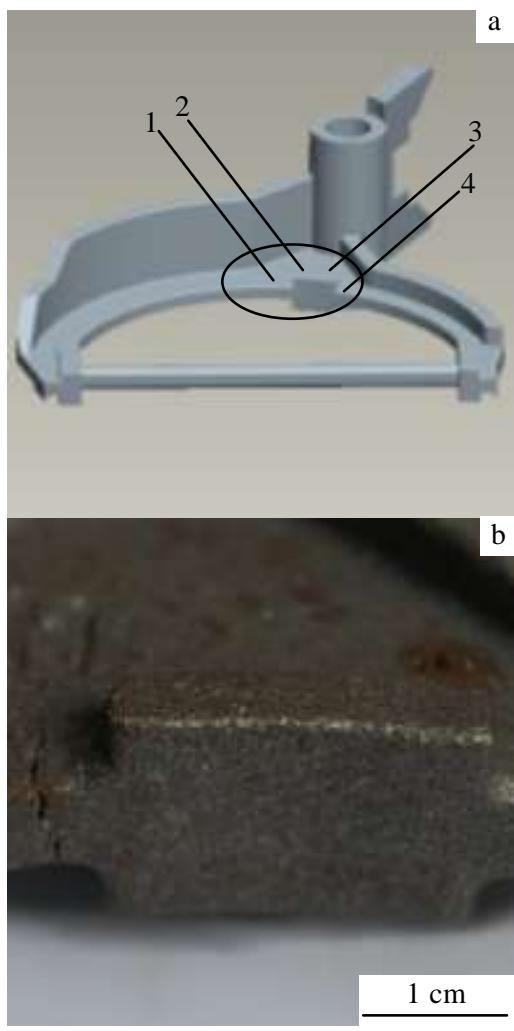

Fig.1 Fork structure (a) and cracked area (b)

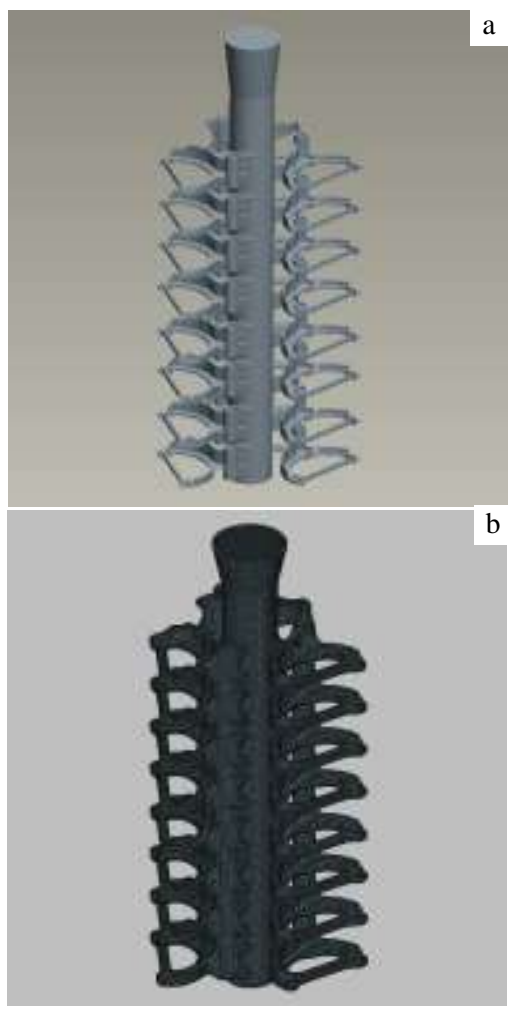

Fig.2 Mold group (a) and the finite element model (b) 


\subsection{Boundary conditions, initial conditions and simulation parameters}

Solidus and liquidus critical temperature of ZG310-570 steel is 1430 and $1510{ }^{\circ} \mathrm{C}$, respectively ${ }^{[8]}$. Smelting equipment is an acidic medium frequency induction furnace. Pouring temperature for investment casting is generally higher than the alloy liquidus temperature by $50 \sim 100{ }^{\circ} \mathrm{C}$. For small castings with complex structure and thin wall, the upper limit is generally used, i.e. the pouring temperature is $1570{ }^{\circ} \mathrm{C}$, the shell is preheated to $850{ }^{\circ} \mathrm{C}$. The casting speed has a great influence on the casting quality. According to the casting experience, the pouring velocity is $70 \mathrm{~mm} / \mathrm{s}$ in the experiment.

Shell material is silica sand; casting and heat transfer coefficient of the shell is $1000 \mathrm{~W} /\left(\mathrm{m}^{2} \cdot \mathrm{K}\right)$; heat transfer coefficient between shell and air is $50 \mathrm{~W} /\left(\mathrm{m}^{2} \cdot \mathrm{K}\right)$; for ZG310-570, heat transfer coefficient of casting and air is 300 $\mathrm{W} /\left(\mathrm{m}^{2} \cdot \mathrm{K}\right)$, and the gravity casting is used.

The Pro-CAST database provides a complete parameter for ZG310-570. Its elastic modulus, yield strength, and hardening coefficient are shown in the following tables. The castings and gating system is meshed by the finite element, 491927 nodes are generated, and 2278121 units are produced.

The tetrahedron grid is adopted, and the large size of the mesh is $0.5 \mathrm{~mm}$, as shown in Fig.2.

\section{Simulation Results and Analysis}

\subsection{Filling sequence}

The filling sequence of the casting is shown in Fig.3. The simulation results show that the sprue is filled with the liquid metal firstly; from the bottom to the top, the cavity is filled with the liquid metal thoroughly in each ingate; under static pressure, each cavity is filled from the bottom to the top in turn, the filling is complete, and the shrinkage defect will not occur in the casting.

\subsection{Temperature field and stress field}

Fig.4a is the casting temperature filed, Fig. $4 \mathrm{~b}$ is the equivalent stress field after pouring completion of $30 \mathrm{~s}$, and the nodes 1, 2, 3, 4 are the points where the hot tearing may occur. The nodes $6,7,8,9$ are the corresponding points for nodes 1, 2, 3, 4. Fig.5 is the solid fraction distribution of the nodes $1,2,3,4$.

Fig.6 is the solid fraction and tensile stress distribution over time. According to the strength theory, the hot cracking occurs at the end of solidification when the solid fraction is greater than 0.9 , almost close to 1.0. At this point, the temperature is between the linear contraction starts and the solidus temperature, the strength is lowest, brittle phase will occur, and the hot cracking is most likely to happen in this area.

Fig. 6 shows that the four nodes solidify almost at the same time at about $24 \mathrm{~s}$. When the solidification starts within $15 \mathrm{~s}$, the solid fraction of each node is less than 0.9 , while there is almost no stress during the process. When it is greater than 0.9 , tensile stress occurs at each node. When it is close to 1.0 , the tensile stress increases sharply; while the tensile stress is the largest at nodes 1 and 2, greater than $60 \mathrm{MPa}$; the solid fraction of the rest nodes is close to 1.0 while the tensile stress is 40 50 MPa.

Comparison is shown in Fig.6. The hot cracking lies between node 1 and 2 . When the solid fraction is close to 1.0 ,

Table 1 Elastic modulus of ZG310-570 steel at different temperatures

\begin{tabular}{ccccc}
\hline Temperature $/{ }^{\circ} \mathrm{C}$ & 20 & 750 & 1250 & 1350 \\
\hline Elastic modulus/MPa & $1.95 \times 10^{5}$ & $0.8 \times 10^{5}$ & $7.0 \times 10^{4}$ & 120 \\
\hline
\end{tabular}

Table 2 Yield strength of ZG310-570 steel at different temperatures

\begin{tabular}{ccccc}
\hline Temperature $/{ }^{\circ} \mathrm{C}$ & 20 & 750 & 1250 & 1350 \\
\hline Yield strength/MPa & 310 & 150 & 12 & 5 \\
\hline
\end{tabular}

Table 3 Hardening coefficient of ZG310-570 steel at different temperatures

\begin{tabular}{ccccc}
\hline Temperature $/{ }^{\circ} \mathrm{C}$ & 20 & 750 & 1250 & 1350 \\
\hline Hardening coefficient/MPa & $1.2 \times 10^{4}$ & $0.8 \times 10^{4}$ & $5 \times 10^{3}$ & 0 \\
\hline
\end{tabular}

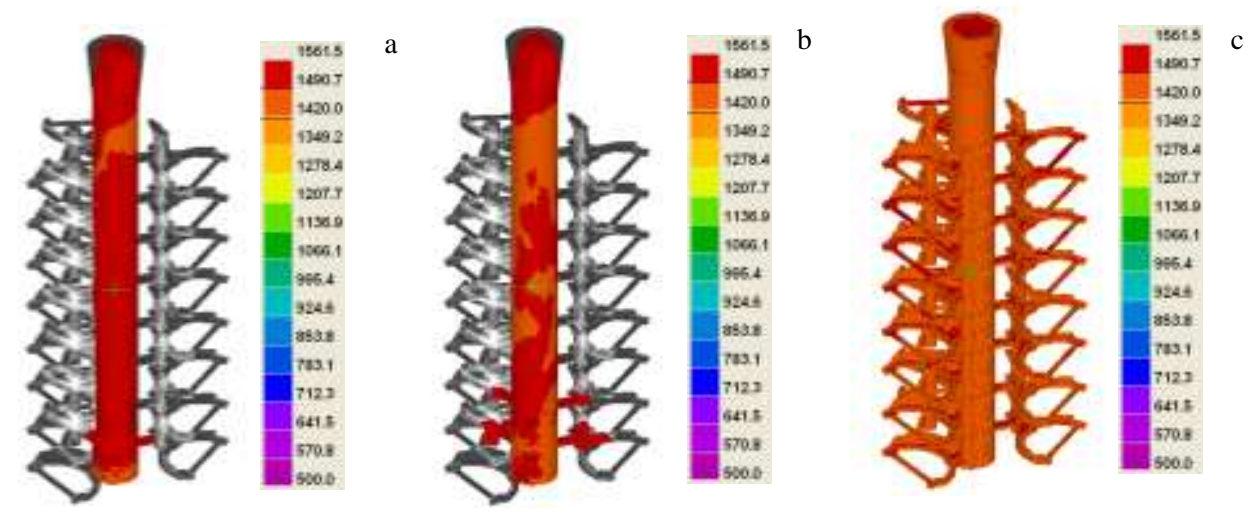

Fig.3 Filling sequence in casting: (a) sprue, (b) the cavity, and (c) each cavity 


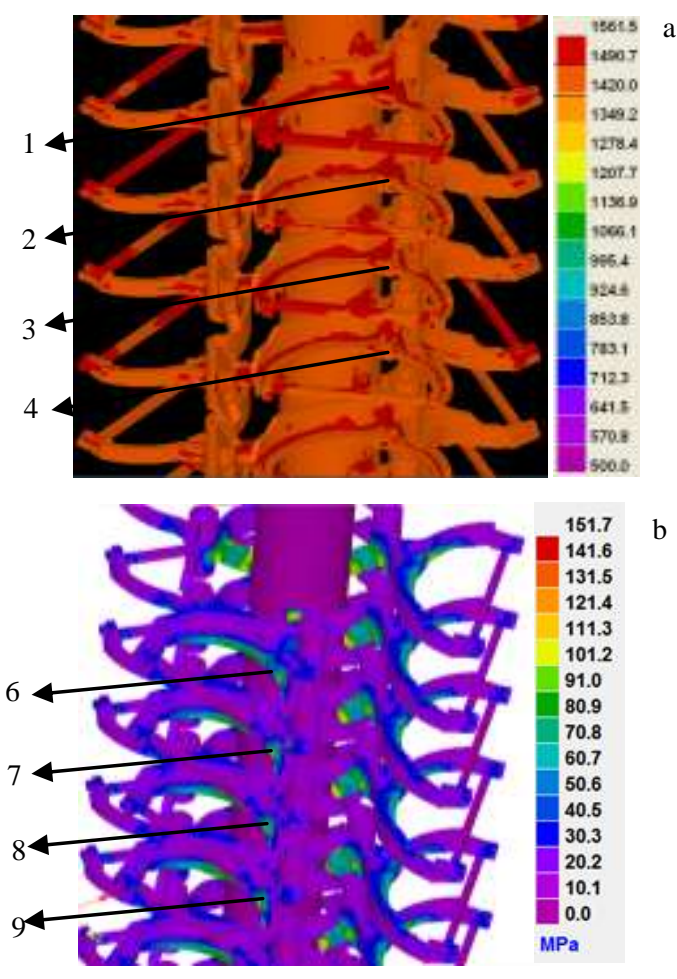

Fig.4 Solidification sequence (a) and stress distribution (b)

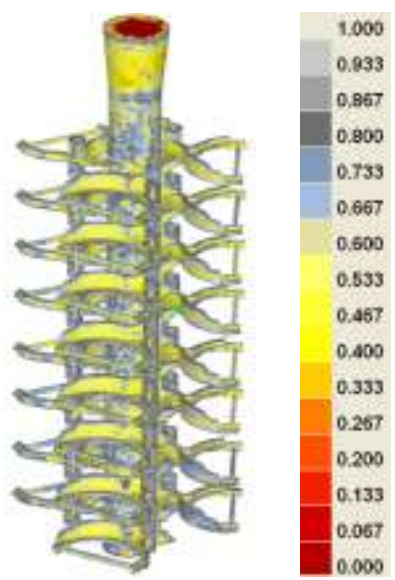

Fig.5 Solid fraction in the casting

the tensile stress occurs at each node. The stress often concentrates near nodes 1 and 2, where the rounded convex curvature is large; therefore, the tensile stress at node 1 and 2 is greater than that of other parts and the hot cracking is most likely to occur.

The stress and strain occur at the first solidification part (as shown in Fig.4b), as the stress and strain accumulate gradually at the final solidification. The shrinkage is blocked,
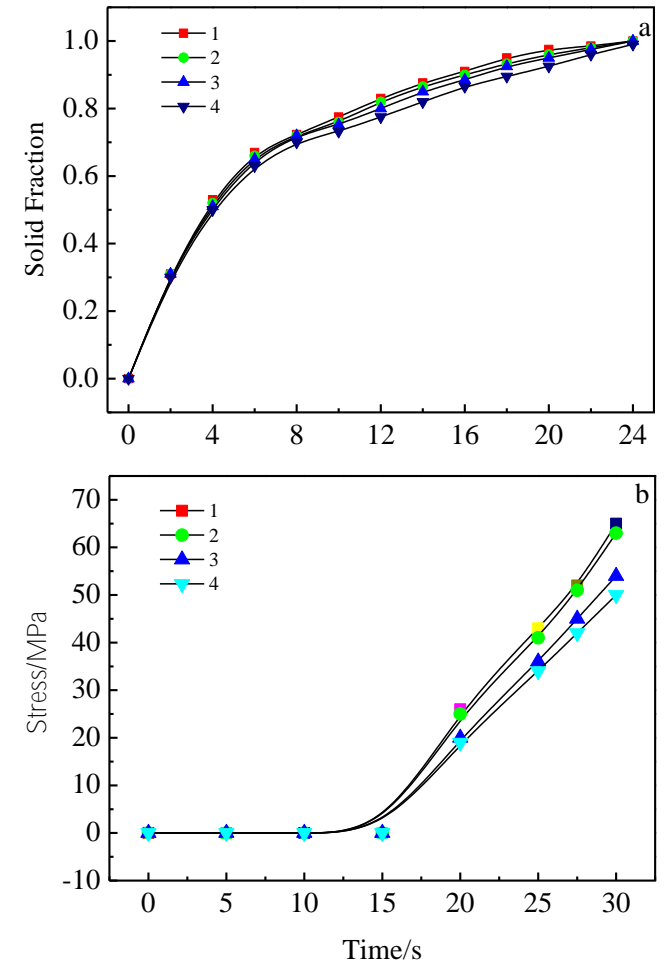

Fig.6 Solid fraction (a) and tensile stress distribution (b) of various nodes

where the stress and strain concentrate, lacking of liquid metal to feed. When the thermal stress is greater than the yield strength, hot cracking occurs.

\subsection{Improved scheme and the simulation results}

In the casting, the higher pouring temperature and mold temperature can ensure the filling ability of the liquid alloy; but when the pouring temperature is too high, the solidification lasts too long, and a large number of coarse grains will be generated, which will increase the tendency of hot cracking. When the pouring temperature and mold temperature is reduced, hot cracking can be avoided, but when the filling temperature and mold temperature is too low, it is difficult to fill the cavity completely.

As there are cracks in the fork, it indicates that the pouring temperature and mold shell heat preservation temperature are too high, and the shell is cooled too quickly, resulting in cracks, so preheating temperature should be increased and pouring temperature should be reduced.

Therefore, while the other casting parameters are kept, the casting pouring temperature is reduced to $1560{ }^{\circ} \mathrm{C}$, and the shell temperature is preheated to $1050{ }^{\circ} \mathrm{C}$

Another way to avoid hot cracking is shown in Fig.7. We can increase the round angle, which is near the point 10; when the round angle is increased, the stress in the casting can be reduced, so the hot cracking can be avoided, as can be seen in Fig.8. 


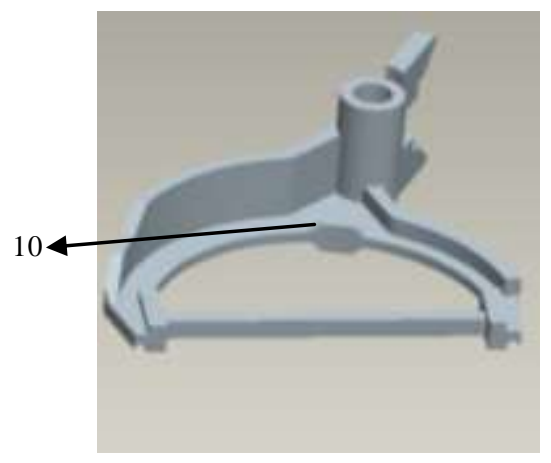

Fig.7 Improved scheme to avoid hot cracking

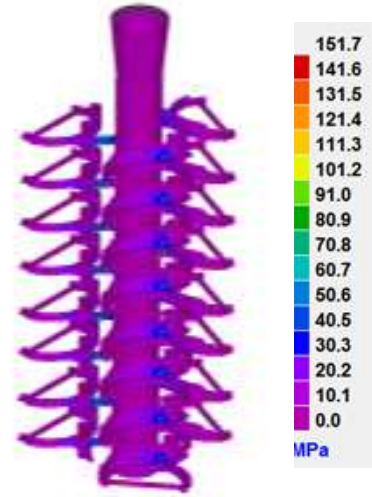

Fig 8 Stress distribution in the solidification

\section{Conclusions}

1) In the investment casting of shifting fork, as the local area receives larger tensile stress from around, the shrinkage cavity appears, leading to crack.

2) By reducing the pouring temperature, increasing preheating temperature of the shell, and increasing round angle of the fork, the casting stress can be reduced, and the crack can be avoided.

\section{References}

1 Monroe C, Beckermann C. Materials Science and Engineering $A[\mathrm{~J}], 2005$, 413-414: 30

2 Eskin D G, Katgerman L. Metallurgical and Materials Transactions $A[\mathrm{~J}], 2007,38(7): 1511$

3 Zhu J Z, Guo J, Samonds M T. International Journal for Numerical Methods in Engineering[J], 2010, 87(1-5): 289

4 Smith R W, Demonte A, Mackay W B F. Journal of Materials Processing Technology[J], 2004, 153-154: 589

5 Wei S Z, Zhu J H, Xu L J. Tribology International[J], 2006, 39(7): 641

6 Clayton P, Sawley K J, Bolton P J et al. Wear[J], 1987, 120(2): 199

7 Cui X H, Shan J, Yang Z R et al. Journal of Iron and Steel Research[J], 2008, 15(4): 67

8 Pawlus P, Galda L, Dzierwa A et al. Wear[J], 2009, 267(11): 1873

\title{
拨叉热裂数值模拟与分析
}

\author{
王明光，蒲 勇 \\ (重庆文理学院 重庆市高校微纳米材料工程与技术重点实验室, 重庆 402160)
}

摘 要: 在采用熔模精密铸造生产拨叉的过程中, 热裂是常见的铸造缺陷。为了充分分析热裂产生的原因, 采用铸造仿真软件Procast 对铸造过程进行模拟，对流场、温度场、应力场进行了模拟和分析，预测和分析热裂产生的位置，结果表明：拨叉铸造过程中，局部区 域应力集中, 在缩孔附近产生热裂纹。通过降低浇注温度, 提高模壳预热温度, 增大凸台过渡倒角, 可以减小应力集中, 从而避免热裂。 关键词: 拨叉; 热裂; 数值模拟

作者简介: 王明光, 男, 1984 年生, 硕士, 重庆文理学院重庆市高校微纳米材料工程与技术重点实验室, 重庆 402160, E-mail: wmg166@163.com 